ORIGINAL ARTICLE

\title{
Outcome of laparoscopic cholecystectomy in terms of intraoperative complications in a tertiary care hospital.
}

\author{
Muhammad Sayyar', Yousaf Jan², Shaukat Hussain ${ }^{3}$
}

Article Citation: Sayyar M, Jan Y, Hussain S. Outcome of laparoscopic cholecystectomy in terms of intraoperative complications in a tertiary care hospital. Professional Med J 2022; 29(1):19-25. https://doi.org/10.29309/TPMJ/2022.29.01.6905

\begin{abstract}
Objectives: The main objective was to evaluate the outcome of laparoscopic cholecystectomy in terms of intra-operative complications and the rate and reasons of conversion to open cholecystectomy. Study Design: Descriptive Study. Setting: Hayatabad Medical Complex, Peshawar. Period: June 2018 to May 2019. Material \& Methods: After taking consent of Hospital ethical \& research committee, patients admitted with clinical diagnosis of cholelithiasis and chronic cholecystitis, confirmed by abdominal ultrasound, undergoing laparoscopic cholecystectomy fulfilling inclusion criteria were selected. Results: A total of 150 were included in the study. Mean age was 39.2yrs with female to male ratio of 9.75:1. Laparoscopic cholecystectomy was successfully accomplished in $98 \%$ cases. In $2 \%$ (3 patients) converted cases the most common cause of conversion observed was dense adhesions in the calots triangle. Intra-operative complications were noted in $1.4 \%$ patients, those included bile duct injury and leakage from the gallbladder bed. However other complications such as bowel injury, blood vessel injury, and post operative hemorrhage did not occur. Overall morbidity was $1.4 \%$ with no mortality. Conclusion: Laparoscopic cholecystectomy is a safe and effective procedure in our setup to the accepted standards, as evident by the national and international studies. And it can be accomplished with minimal morbidity and low rate of conversion with the increasing surgeon's experience.
\end{abstract}

Key words: Cholelithiasis, Chronic Cholecystitis, Laparoscopic Cholecytectomy.

\section{INTRODUCTION}

Gallstones are the most common biliary pathology and is the major health problem in adult population worldwide. ${ }^{1,2}$ The prevalence of cholelithiasis in adults in USA is $10-15 \%$ and in Europe is approximately $18.5 \% .^{3}$ Also in Pakistan it is the third most common cause of hospital admissions though data available is scanty but it accounts for $14 \%^{4}$ and $16 \%{ }^{5}$ according to data obtained from Karachi. ${ }^{6}$ More than $80 \%$ of gallstones are asymptomatic while $1-2 \%$ of asymptomatic patients ultimately may develop symptoms requiring surgical removal, making cholecystectomy one of the most common operations performed by general surgeons. ${ }^{1}$

Modern surgical endoscopes were first developed in early 1800s. Modern Laparoscopic surgery is becoming popular alternative to traditional open surgical procedures. This is exemplified by introduction of laparoscopic cholecystectomy, which attracted only minor curiosity when first performed in 1987 in France by Mouret. $^{7}$ Laparoscopic cholecystectomy was carried out in United States during the latter part of 1988 by McKernan and Saye and shortly thereafter by Reddick and Oslen. The procedure was then widely disseminated during 1989 and 1990 and superseded open cholecystectomy with rapidity that has never seen before. The first laparoscopic cholecystectomy was performed in Pakistan in 1991.

It has rapidly become the "gold standard" for the elective management of cholelithiasis and chronic cholecystitis. ${ }^{8,9,10}$ It is now increasingly used for cholecystectomy in acute cholecystitis. ${ }^{11,12}$ It is usually safe and cost effective leading to short
1. MBBS, FCPS, Senior Medical Officer Surgery, THQ, Shabqadar.

2. FCPS, MRCS, FRCS (General Surgery), Assistant Professor General Surgery, Hayatabad Medical Complex, Peshawar.

3. MBBS, Medical Officer General Surgery, Hayatabad Medical Complex, Peshawar.

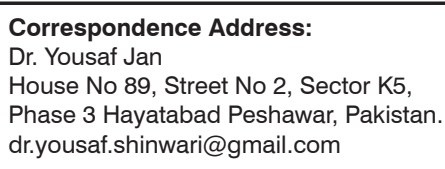

Correspondence Address:

Dr. Yousaf Jan

House No 89, Street No 2, Sector K5, Phase 3 Hayatabad Peshawar, Pakistan. dr.yousaf.shinwari@gmail.com

Article received on: Accepted for publication: 
hospital stay, less post operative pain, less complications, rapid return to normal activity and decreased mortality and morbidity. ${ }^{13,14}$

A number of complications have been reported with laparoscopic cholecystectomy with the frequency of $3.6 \% .{ }^{11}$ These includes common bile duct injury, cystic duct injury, bleeding from gall bladder bed, duodenal injury, colonic injury, retained stones in common bile duct. ${ }^{13,14}$ The anesthesia related complications are intra-operative hypotension, arrhythmias, and increase in end-tidal-carbon dioxide. ${ }^{15}$ The risk of intra-operative injury during laparoscopic cholecystectomy is higher than in open cholecystectomy and it decline with increasing surgical experience and intra-operative use of cholangiography. ${ }^{16}$

Laparoscopic cholecystectomy is converted to open cholecystectomy if there is inability to identify anatomical structures correctly due to dense adhesions ${ }^{17}$, hemorrhage, bile duct injury, difficult dissection in calot's triangle, choledocholithiasis, and gall bladder cancer and if there is gut injury which is recognized during the procedure. ${ }^{18}$

The intra-operative complications in laparoscopic cholecystectomy have been debated in the West for the last decade and the intra-operative injury is higher than that in open cholecystectomy. It has been anticipated that this will diminish with increasing surgeon's experience in the use of laparoscopic cholecystectomy. Our local data is relatively scarce in this regard. This study will furnish important local epidemiologic data regarding the various outcome measures of laparoscopic cholecystectomy in our set up. This will help to improve the existing situation with a positive influence on the overall management of our patients.

\section{MATERIAL \& METHODS}

This Descriptive study was conducted in the department of Surgery, Hayatabad Medical Complex Peshawar, from 01-06-2018 to 31-052019 after taking consent of Hospital ethical and research committee. The sample size was 150 patients, with $90 \%$ power of test and level of significance is $5 \%$ under WHO software for sample size determination the sampling technique used was Non-probability consecutive sampling.

All patients of either gender aged over 14yrs with cholelithiasis and/or chronic cholecystitis, who underwent laparoscopic cholecystectomy. Patients not consented to participate in the study or those not willing for laparoscopic cholecystectomy, patients with acute cholecystitis, previous abdominal surgery, choledocholithiasis and patients with serious co morbidity were excluded from the study.

Patients fulfilling the inclusion criteria were included in the study; informed written consent was taken from all patients for participation in the study. Patients were assessed by adequate history, thorough examination and investigations (ultrasound abdomen, liver function tests in all patients, other investigations such as X-ray chest, ECG, complete blood count, blood sugar level, renal function tests where indicated). Patients diagnosed by ultrasound abdomen having cholelithiasis were selected for laparoscopic cholecystectomy. Pneumoperitoneum was created by Hassan technique and standard four ports were used for laparoscopic cholecystectomy. All complications, conditions leading to conversions of laparoscopic to open cholecystectomy were noted on the preformed proforma. All the data was recorded and observed by myself to exclude any bias in my study.

The data was analyzed through SPSS version 10 and various descriptive statistics were used to calculate frequencies, percentages, means and standard deviations. The numerical data such as age, gender were expressed as mean \pm standard deviation while the categorical data such as bile duct injury, blood vessel injury, bowel injury, post operative hemorrhage and causes of conversion like dense adhesions, CBD exploration etc. were expressed as frequency and percentages. The results were projected as tables and graphs.

\section{RESULTS}

One hundred and fifty patients were included in this study. 136 out of these 150 were females and 
14 were male with the Female to male ratio of 9.7:1 (Table-I). Age of these patients ranged from $15-80$ years with the mean age 39.2years.

Laparoscopic cholecystectomy was successfully accomplished in 147 patients (98\%). Conversion to open cholecystectomy was required in only three patients (2\%). Dense adhesions at the Calot's triangle were the single most common cause for conversion shown in (Table-III and Table-IV).

Complications occurred in 2 patients (1.4\%) shown in Table-II, both these complications were not identified at the time of surgery and were picked up postoperatively: these were common bile duct injury and leakage from gallbladder bed. Other complications including bowel injury, blood vessel injury and postoperative hemorrhage did not occur.

\begin{tabular}{|l|c|c|c|c|}
\hline & Age & Gender & $\begin{array}{c}\text { Fre- } \\
\text { quency }\end{array}$ & \%age \\
\hline N & 150 & Male & 14 & 9.3 \\
\hline Mean & 39.2000 & Female & 136 & 90.7 \\
\hline Std. Deviation & 11.2673 & Total & 150 & 100.00 \\
\hline
\end{tabular}

Table-I. Mean, Standard deviation, Age range of patients \& gender wise distribution.

\begin{tabular}{|c|c|c|c|}
\hline No. & Complications & Frequency & Percentage \\
\hline 1 & Bile duct injury & $1 / 150$ & 0.7 \\
\hline 2 & Bowel injury & $0 / 150$ & 0 \\
\hline 3 & Blood vessel injury & $0 / 150$ & 0 \\
\hline 4 & $\begin{array}{c}\text { Post-operative } \\
\text { hemorrhage }\end{array}$ & $0 / 150$ & 0 \\
\hline 5 & $\begin{array}{c}\text { Other (leakage from } \\
\text { gallbladder bed) }\end{array}$ & $1 / 150$ & 0.7 \\
\hline & $\begin{array}{c}\text { Total } \\
\text { Table-II. Frequency of complications in patient's } \\
\text { undergone laparoscopic cholecystectomy. }\end{array}$ \\
\hline \multicolumn{3}{|c|}{} \\
\hline
\end{tabular}

\begin{tabular}{|l|c|c|}
\hline Conversion to Open & Frequency & Percent \\
\hline Yes & 3 & 2.0 \\
\hline No & 147 & 98.0 \\
\hline Total & 150 & 100.0 \\
\hline
\end{tabular}

Table-III. Frequency table of conversion of laparoscopic cholecystectomy into open cholecystectomy.

\begin{tabular}{|l|c|c|}
\hline $\begin{array}{c}\text { Reasons of } \\
\text { Conversion }\end{array}$ & Frequency & Percent \\
\hline Dense adhesions & 3 & 2.0 \\
\hline Total & 150 & 100.0 \\
\hline \multicolumn{1}{|c|}{ Table-IV. Frequency distribution of reasons of } \\
conversion to open cholecystectomy.
\end{tabular}

\section{DISCUSSION}

Laparoscopic surgery has changed the field of surgery since 1987, when first laparoscopic cholecystectomy was performed and with the experience its application has expanded rapidly and it has become the gold standard for the elective management of cholelithiasis and chronic cholecystitis. ${ }^{8,9,19}$ It is the commonest operation performed laparoscopically world wide. It is usually safe and cost effective. With the introduction of laparoscopic cholecystectomy there is a continuous decrease in the number of open cholecystectomies, in the developed countries open cholecystectomies account for less than $20 \%$ of all the cholecystectomies performed. ${ }^{20,21}$ While in the developing countries like Pakistan open procedure is still common due to lack of skills and unavailability of laparoscopic apparatus, the reported rate of open procedures in our country is $80 \%$ by Abbasi et $\mathrm{al}^{22}, 21.3 \%$ by Raza et $\mathrm{al}^{2}$, and $32 \%$ by lqbal et al. ${ }^{23}$

The present study elaborates the intra-operative complications and rate and reason of conversion to open procedure, no surgical procedure is without complications. A number of complications have been reported to occur with the laparoscopic cholecystectomy also.

Complications like injuries related to insertion of trocar such as vascular and gut injuries are reported by Diziet et al. ${ }^{24}$ They reported 13 cases of aortic injury with single case of mortality. Similarly Raviaco et al. ${ }^{25}$ reported one aortic injury and one to the middle colic artery. ${ }^{26}$ In our study no port insertion related complications were noted.

In our study majority of the patients were female $(90-97 \%)$, which is consistent with the national and internationmal studies. ${ }^{21,27,28}$ Mean age and minimum age is slightly less than reported in other study. ${ }^{20}$ Serious complications occur in 
laparoscopic cholecystectomy fewer than $2 \%$ of all cases. ${ }^{29}$ In our study the complication rate was $1.4 \%$ which is within the range and published reports $(0.8-6 \%){ }^{30}$ The overall complication rate in our study $(1.4 \%)$ is far less than other studies, like Wagih Ghnnam et $\mathrm{al}^{30}(3.24 \%)$ and Husseini et al $(3.6 \%) .{ }^{11}$

The two complications occurred in this study were: Single case of leakage from gallbladder bed $(0.7 \%)$ and a single case of CBD injury $(0.7 \%)$. The most debated issue has been the incidence of the common bile duct injury. The reported incidence of bile duct injury is between $0 \%-1 \%$ in laparoscopic cholecystectomy. ${ }^{29,31,32}$ Whereas in open cholecystectomy the overall risk of injury to CBD is $0.1-0.2 \%{ }^{33}$

Whereas recent studies describe, experience of surgeon to be the most important risk factor for CBD injury i.e. when performed by experienced surgeon the incidence of CBD injury is less than $1 \%(0-0.8 \%){ }^{34} \mathrm{CBD}$ injury during laparoscopic cholecystectomy is an iatrogenic catastrophe associated with significant post operative morbidity and mortality, reducing the long term survival and quality of life of patient. ${ }^{35}$ In United States of America and Britain 34-44\% of surgeons have successfully cured a major bile duct injury of one to two such cases. ${ }^{36}$ Evidence suggests that CBD injury should be managed by an experience hepatobiliary surgeon, and an early recognition of the injury affects directly on the outcome.

CBD injury if treated by surgeon has an increased risk of mortality (11\%) at 9 years. ${ }^{37}$ Most CBD injuries occur within the surgeons first 100 cholecystectomies. One third happen after surgeon has performed 200 cases. $^{36}$ It has been suggested that commonest cause of injury to bile duct is inability to properly diagnose the biliary anatomy as a result three quarter of such injuries are not recognized at the time of injury. ${ }^{37}$

According to three population based studies, intraoperative cholangiogram has reduced the risk of bile duct injury, whereas in other studies cholangiography does not prevent injury rather correct interpretation of anatomy can prevent this complication. ${ }^{37}$ Though there is controversy of performing intraoperative cholangiography, there is enough evidence in favor of peroperative cholangiogram as it is likely to identify the injury at the time of surgery. As reported by Archer et al. $81 \%$ of CBD injuries were detected at the time of surgery when peroperative cholangiogram were done as compared to $45 \%$ when not done. ${ }^{36}$

In our study both the complications were not detected at the time of surgery. For which later explorations were done and both were managed accordingly. Though these complications were less $(1.4 \%)$ as compared to other studies as mentioned, still these can be prevented with the increasing surgeons experience and availability of peroperative cholangiogram.

In our study three cases out of one hundred and fifty were converted to open cholecystectomy so the conversion rate became $2 \%$ and the most common cause of these conversions was dense adhesions in the Calot's triangle. Conversion to open procedure is also related to surgeons experience in laparoscopic procedures but also the degree of difficulty during the procedure. There is a widely variable rates of conversions ranging from $2 \%-15 \%$ in different national and international centers ${ }^{38}$, with higher rates of conversion to open procedure in the developing countries as compared to the developed countries. $^{39}$

Other reasons for conversion to open included hemorrhage in Calot's triangle, injury to stomach and gut, slipped liga clips, instrument failure etc. ${ }^{13,23}$ but we did not encounter these problems in our study. Our observation show fairly improved results as compared to other studies. Comparison of conversion rates are shown in table below.

\begin{tabular}{|c|l|c|}
\hline Serial No & \multicolumn{1}{|c|}{ Study } & Conversion Rates \\
\hline 1 & ${\text { Tariq Saeed et } \mathrm{al}^{26}}$ & $5 \%$ \\
\hline 2 & ${\text { Wagih Ghnnam et } \mathrm{al}^{30}}^{30}$ & $5 \%$ \\
\hline 3 & Saeed et al $^{38}$ & $3.2 \%$ \\
\hline 4 & Raza et al $^{2}$ & $11.11 \%$ \\
\hline 5 & Shammim et al $^{13}$ & $7.5 \%$ \\
\hline 6 & Our study & $2 \%$ \\
\hline
\end{tabular}

Table-V. Comparison of conversion of laparoscopic to open cholecystectomy in various studies. 
Old age i.e. above 60 was predicting risk factor of conversion in Wagih Ghnnam et al ${ }^{30}$ study but in our study mean age of converted cases was 52 years and less than 60 years. Our observation of conversion to open in patients of age more than 50 years is also supported by Simopoulos et $\mathrm{al}^{40}$ and kanaan et al. ${ }^{41}$ Showing successful laparoscopic cholecystectomy in younger patients while patients requiring conversion had mean age more than 50 .

Our all converted cases were female which is also supported by study of Rosen et $\mathrm{al}^{42}$ showing that male sex is not risk factor for conversion to open. On the other hand Wagih Ghnnam et al and simopolous et al showed male patients to have increased risk of difficult and unsuccessful LC.

\section{CONCLUSION}

The surgical experience and new laproscopic techniques have proved that laparoscopic cholecystectomy is a safe and effective procedure in our setup to the accepted standard as compared to the national and international studies. Availability of instruments and proper training of new surgeons are the main areas of concern to further improve the outcome of LC.

\section{Copyright $@ 17$ May, 2021.}

\section{REFERENCES}

1. William NS, Blustrade C.J.K, O'Connell PR. The gall bladder and bile duct. In: Bailey and Love's short practice of surgery: $25^{\text {th }}$ ed. Great Britain: 2008.

2. Raza M, Wasty WH, Habib L, Farhat J, Saria MS, Sarwar M. An audit of cholecystectomy. Pak J Surg 2006; 23(2):100-103.

3. Schimer BD, Winter XL, Edlich RF. J Longterm Eff Med implants 2005; 15(3):329-38.

4. Jawaid M, Masood Z, Iqbal SA, Sultan T. The pattern of diseases in a Surgical Unit at tertiary care public hospital at Karachi. Pak J Med Sci 2004; 20(4):311314.

5. Alam SN, Rehman S, Raza SM, Manzir SM. Audit of general surgical unit: Need for self evaluation. Pak J Surg 2007; 23(2):141-144.

6. Gadaor TR, Talamzii MA. Traditional vs Laparoscopic cholecystectomy. Am J Surg 1999; 16(1):336-8.
7. Mouret P. From the first laparoscopic cholecystectomy to the frontiers of laparoscopic surgery: The prospective futures. Dig Surg 1991; 8(3):124-27.

8. Al-Salmah SM. Outcome of laparoscopic cholecystectomy in acute cholecystitis, J Coll Physician Surg Pak 2005; 15(2):400-403.

9. Johansson M, Thune A, Nelvin L, Lundell L. Randomizeed clinical trial of day care versus overnight stay Laparoscopic cholecystectomy. $\mathrm{Br} \mathrm{J}$ Surg 2006; 93(1):40-45.

10. Southern Surgeon Club, A prospective analysis of 1518 Laparoscopic cholecystectomies. N Engl J Med 1991; 324(16):1073-8.

11. Hosseini SN, Mousavinasab SN, Rahmanpoor $\mathrm{H}$. Outcome of laparoscopic cholecystectomy in acute and chronic cholecystitis. J Coll Physicians Surg Pak 2007; 17(7):406-9.

12. Lee HK, Han HS, Min SK, Lee JH. Sex based analysis of the outcome of the laparoscopic cholecystectomy for acute cholecystitis. Br J Surg 2005; 92(4):463-6.

13. Shamim M, Dahri MM, Memon AS. Complications of laparoscopic cholecystectomy. Pak J Surg 2006; 25(1):70-7.

14. Shahzad K, Mian MA, Rehman J. Early complication of laparoscopic cholecystectomy for calculous cholecystitis. Pak Armed Forces Med J. 2007; 57(4):289-94.

15. Qureshi FA. Anaesthesia related complications of laparoscopic cholecystectomy. J Coll Physicians Surg Pak 2003; 13(7):369-71.

16. Hobbs MS, Mai Q, Knuiman W, Flelcher R, Ridout SC. Surgeons experience and trends in intraoperative complications in laparoscopic cholecystectomy. $\mathrm{Br}$ J Surg 2006; 93(7):844-53.

17. Shea JA, Haeley MJ, Berlin JA, Clarke JR, Malet PF, Staroscik RN, et al. Mortality and complications associated with laparoscopic cholecystectomy. A meta analysis. Ann Surg 1996; 244(3):609-20.

18. Ali M, Gondal SH, Rana HN, Ali M. Early conversion is a safe option to avoid complications in laparoscopic cholecystectomy for the beginners. Ann King Edward Med Coll 2006; 12(2):15-17.

19. Sari YS, Tunali V, Tomaoglu K, Karagöz B, Güneyi A, Karagöz I. Can bile duct injuries be prevented? A new technique in laparoscopic cholecystectomy. BMC Surg 2005; 5(1):5-14. 
20. Tarcoveanu E, Nicculesce D, Georgescu S, Bradea C. Epure conversion in laparoscopic cholecystectomy. Chirugia. 2005; 100(5):437-44.

21. Bhopal FG, Rai MA, lqbal MA. A comparative study of morbidity in laparoscopic and open cholecystectomy. J Surg Pak. 1998; 3(3):2-7.

22. Abbassi SA, Azami R Haleem A. An audit of Laparoscopic cholecystectomy performed at PNS Shifa. Pak Armed Force Med J 2003; 53(1):51-8.

23. Iqbal J, Iqbal $Q$, Ahmad B, TI MA. Laparoscopic V/s Open Cholecystectomy. The Professional Medical Journal. 2002 Sep 12; 9(03):226-35.

24. Roviaro GC, Macioco M, Rebuffat C, Varoli F, Vergani V, Rabughino G, et al. Complications following cholecystectomy. J Roy Coll Surg Edinb 1997; 42(1):324-8.

25. Jaffary SA, Shamim MS, Raza SJ, Dastagir A. Instrument failure; A preventable cause of conversion in laparoscopic cholecystectomy. Pak J Surg 2006; 23(2):92-5.

26. Mufti TS,Ahmad S, Naveed D, Akbar M, Zafar A, Laparoscopic cholecystectomy: An early experiance at Ayub teaching hospital abbottabad, J Ayub Med Coll Abbottabad 2007; 19(4): 42-40.

27. Ji W, Li LT, Li JS. Role of laparoscopic subtotal cholecystectomy in the treatment of complicated cholecystitis. Hepatobilpancreatic Dis Int. 2006; 5(4):584-9.

28. Purkayastha S, Tilney HS, Georgiou P, Athanasiou T, Tekkis PP, Darzi AW. Laparoscopic cholecystectomy versus mini-laparotomy cholecystectomy: A metaanalysis of randomised control trials. Surg Endosc. 2007; $21(8): 1294-1300$.

29. Hunter JG, Thompson SK Laparoscopic cholecystectomy, intraoperative cholangiography and common bile duct exploration. In: Mastery of Surgery 2007; 5(1):116-19.

30. Ghnnam W, Malek J, Shebl E, Elbeshry T, Ibrahim A, Rate of conversion and complications of laparoscopic cholecystectomy in a tertiary care centre in Saudi Arabia. Ann Saudi Med 2010; 30(2):145-148.
31. Gouma DJ, Opertop $\mathrm{H}$, management of bile duct injuries: Treatment and Ionterm results. Dig Surg 2002; 19(2):117-22.

32. Vagenas K, Karamanakos SN, Spyropoulos C, Panagiotopoulos S, Karanikolas M, Stavropoulos M, laparoscopic cholecystectomy: A report from a single centre. World J Gastroentrol 2006; 12(5):388790.

33. Nair RG, Dunn DC, Fowler S, McCloy RS, Progress with cholecystectomy: Improving results in England and Wales. Br J Surg 1997; 84(3):1396-8.

34. Lujan JA, Parrilla P, Robles R, Torralba JA, Garcia-Ayllon J, Liron R, et al. Laparoscopic cholecytectomy in the treatment of acute cholecystitis, J Am Coll Surg 1995; 181(9):75-77.

35. Connor S, Garden OJ. Bile duct injury in the era of laparoscopic cholecystectomy. $\mathrm{Br} J$ Surg 2006; 93:158-168.

36. Archer SB, Brown DW, Smith CD, Branum GD, Hunter JG. Bile duct injury during laparoscopic cholecystectomy: Results of a national survey. Ann Surg 2001; 234:549-559.

37. Hugh TB. New strategies to prevent laparoscopic bile duct injury-Surgeons can learn from pilots. Surgery 2002; 132:826-835.

38. Bhopal FG, Rai MA, lqbal MA. A comparative study of morbidityin laparoscopic and open cholecystectomy. J Surg Pak.1998; 3(3):2-7.

39. Elder S, Qunin J, Chourih, Sabo E, Matter I, Nashe E, Schein M. Safety of laparoscopic cholecystectomy in a teaching services: A prospective trial. Surg Lap Endosc 1996; 6(3):218-20.

40. Simopoulos C, Botaitis S, Polychronidis A, Tripsianis G, Karayiannakis AJ. Risk factors for conversion of laparoscopic cholecystectomy to open cholecystectomy, Surg Endosc 2005; 19(4):905-9.

41. Kanaan SA, Murayama KM, Merriam LT, Dawes LG, Prystowsky JB, Rege RV. Risk factors for conversion of laparoscopic to open cholecystectomy. J Surg Res 2002; 106(2):20-4.

42. Rosen M, Brody F, Ponsky J. Predictive factors for conversion of laparoscopic cholecystectomy. Am J Surg 2002; 184(3):254-8. 


\begin{tabular}{|c|l|l|c|}
\hline \multicolumn{3}{|c|}{ AUTHORSHIP AND CONTRIBUTION DECLARATION } \\
\hline No. & \multicolumn{1}{|c|}{ Author(s) Full Name } & \multicolumn{1}{|c|}{ Contribution to the paper } & Author(s) Signature \\
\hline 1 & Muhammad Sayyar & Data collection. & Sogs \\
\hline 2 & Yousaf Jan & Data interpretation. & \\
\hline 3 & Shaukat Hussain & Review article at end. & \\
\hline
\end{tabular}

